\title{
Association of pulse rate with obesity
}

\begin{abstract}
Objective of this study was to correlate the pulse rate with obesity. Pulse is the circulation of blood in the arteries. Different people have different pulse rate depending on their body's physical needs. Fast pulse rate may lead to the serious disorders. Obesity develops due to poor diet. Lack of regular exercise causes a person to become obese. For checking pulse rate, we placed our two fingers on our wrist and started to count down the pulses for about one minute. It was concluded that there was significant association between pulse rate and obesity.
\end{abstract}

Keywords: pulse rate, cardiac disorders, obesity, medication
Volume 12 Issue I - 2019

Muhammad Imran Qadir, Sana lqbal

Institute of Molecular Biology and Biotechnology, Bahauddin

Zakariya University, Multan, Pakistan

Correspondence: Sana Iqbal, Institute of Molecular Biology and Biotechnology, Bahauddin Zakariya University, Multan, Pakistan,Email sana39544@gmail.com

Received: January 24, 2019 | Published: February 12, 2019

\section{Introduction}

A pulse is the circulation of the blood through the arteries. And pulse rate is a speed that can be measured by the contractions of the heart per minute. Different people have different pulse rate depending upon their body's physical needs, for example intake of oxygen and excretion of carbon dioxide. There are different activities than can affect the pulse rate. It includes stress, sleep, intake of drugs and physical illness. Normal pulse rate of children is about 70 to $100 \mathrm{bpm}$. And adults pulse rate ranges from 60 to $100 \mathrm{bpm}$. A pulse rate may be too slow or too fast and it can lead to the serious disorders. A very fast pulse rate leads to the cardiac diseases and very slow pulse rate may cause the head injury. There are three pulse sites from where we can take the pulse of the patients i.e. wrist, throat and inside of our elbow. ${ }^{1}$ When person gains more weight than his normal body weight, this is called obesity. Usually obesity develops due to our poor diet like eating too much fast food, drinking alcohol and other fatty foods. Physical activities are major causes of obesity. Lack of these physical activities like regular exercise causes a person to become obese. Obesity causes many health problems like heart diseases, osteoarthritis and cancer etc. In order to overcome the obesity, we should do more exercise after eating, don't use fatty foods and alcohol. Otherwise it may cause the death of the patient. Obesity can also be treated by taking certain weight loss medications. ${ }^{2}$ Objective of this study was to associate the pulse rate and obesity.

\section{Materials and method}

For checking the pulse rate, we placed our two fingers on wrist in between bone and tendon over radial artery. After feeling pulse, we started to count down our heart beats for about 1 minute. For analyzing the relationship of pulse rate with obesity, we operated a survey among different pupils. Each pupil informed us about his pulse rate. Total of 183 individuals participated in this survey. They were the pupils of Bahauddin Zakariya University, Multan, Pakistan.

\section{Statistical analysis}

By the use of MS Excel we performed statistical analysis. $t$-Test was also used to analyze the results.

Table I Statistical analysis of obese and non-obese subject

\begin{tabular}{ll}
\hline Obese & Non-obese \\
\hline $76.027778 \pm 11.107342$ & $79.65753 \pm 10.07227$ \\
\hline
\end{tabular}

\section{Results and discussion}

Different results are as follows:

Obese subjects had average pulse rate was 76.027778 with standard deviation about 11.107342. And non-obese subjects had average pulse rate was 79.65753 with their standard deviation 10.07227 . By performing $t$-Test, we obtained a $p$-value. If the $p$-value was greater than 0.05 then results were non- significant. If $p$-value was less than 0.05 then results were significant. But in this survey results were significant $(p<0.05)$. Questionnaire based studies in the recent researches have given an important advancement. Similar surveys were also done by Elsworth Buskirk, Henry Longstreet and Ernst Simonson. ${ }^{3-10}$

\section{Conclusion}

It was concluded from above survey that there was significant association between pulse rate and obesity.

\section{Acknowledgments}

None.

\section{Conflicts of interest}

Authors declare that there is no conflict of interest.

\section{References}

1. Qadir MI, Malik SA. Comparison of alterations in red blood cell count and alterations in hemoglobin concentration in patients suffering from rectal carcinoma undergoing 5-fluorouracil and folic acid therapy. Pharmacologyonline Nl. 2010;3:240-243.

2. Qadir MI, Noor A. Anemias. Rare \& Uncommon Diseases. England: Cambridge Scholars Publishing Newcastle; 2018.

3. Qadir MI, Javid A. Awareness about Crohn's Disease in biotechnology students. Glo Adv Res J Med Medical Sci. 2018;7(3):062-064.

4. Qadir MI, Saleem A. Awareness about ischemic heart disease in university biotechnology students. Glo Adv Res J Med Medical Sci. 20187(3):059-061.

5. Qadir MI, Ishfaq S. Awareness about hypertension in biology students. Int J Mod Pharma Res. 2018;7(2):08-10.

6. Qadir MI, Mehwish. Awareness about psoriasis disease. Int $J$ Mod Pharma Res. 2018;7(2):17-18.

7. Qadir MI, Shahzad R. Awareness about obesity in postgraduate students of biotechnology. Int J Mod Pharma Res. 2018;7(2):14-16. 
8. Qadir MI, Rizvi M. Awareness about thalassemia in post graduate students. MOJ Lymphology \& Phlebology. 2018;2(1):14-16.

9. Qadir MI, Ghalia BA.Awareness survey about colorectal cancer in students of M. Phil Biotechnology at Bahauddin Zakariya University, Multan, Pakistan. Nov Appro in Can Study. 2018;1(3):NACS.000514.2018.
10. Qadir MI, Saba G. Awareness about intestinal cancer in university student. Nov Appro in Can Study. 2018;1(3):NACS.000515.2018. 